\title{
“Double-surgical-mask-with-slit” method: reducing exposure to aerosol generation at upper gastrointestinal endoscopy during the COVID-19 pandemic
}

The COVID-19 pandemic has highlighted the risk of spread of disease through infected aerosols. Thus, as any endoscopic procedure involving the upper gastrointestinal (Gl) tract is recognized as an aerosol-generating procedure, it mandates the use of full personal protective equipment [1]. As aerosols may remain airborne within the endoscopy room for hours, several novel devices have been proposed for their further containment $[2,3]$.

In order to reduce environmental contamination with potentially infective aerosols, we developed a simple and inexpensive double surgical mask with a slit to be used for patient wear during endoscopy procedures involving the upper GI tract.

This method uses two disposable surgical masks, taped over each other. Scissors are used to cut a narrow slit of length $1.2 \mathrm{~cm}$ that will just allow snug passage of the endoscope ( $\mathbf{F i g . 1}$ ). The double mask is then worn by the patient, covering the mouthguard and oxygen delivery cannulas. Despite its snug fit, the narrow slit still allows easy passage of the endoscope ( $>$ Fig. 2) and any required suction of the oral cavity, while the double mask itself (and its curtainlike slit) minimizes any "leakage" of generated aerosols.

Surgical mask use appears to truncate the "shotgun effect" of how aerosols travel through the air at the point of generation [4]. We have drawn on this principle to adapt these universally available and inexpensive materials to reduce exposure to potentially infective aerosols during endoscopic procedures involving the upper GI tract. Although we appreciate that studies to quantify any mitigation of aerosol risk would be required, from our experience, this simple method could be widely applied in routine clinical practice, as also discussed recently at the international webinar "COVID-19 in

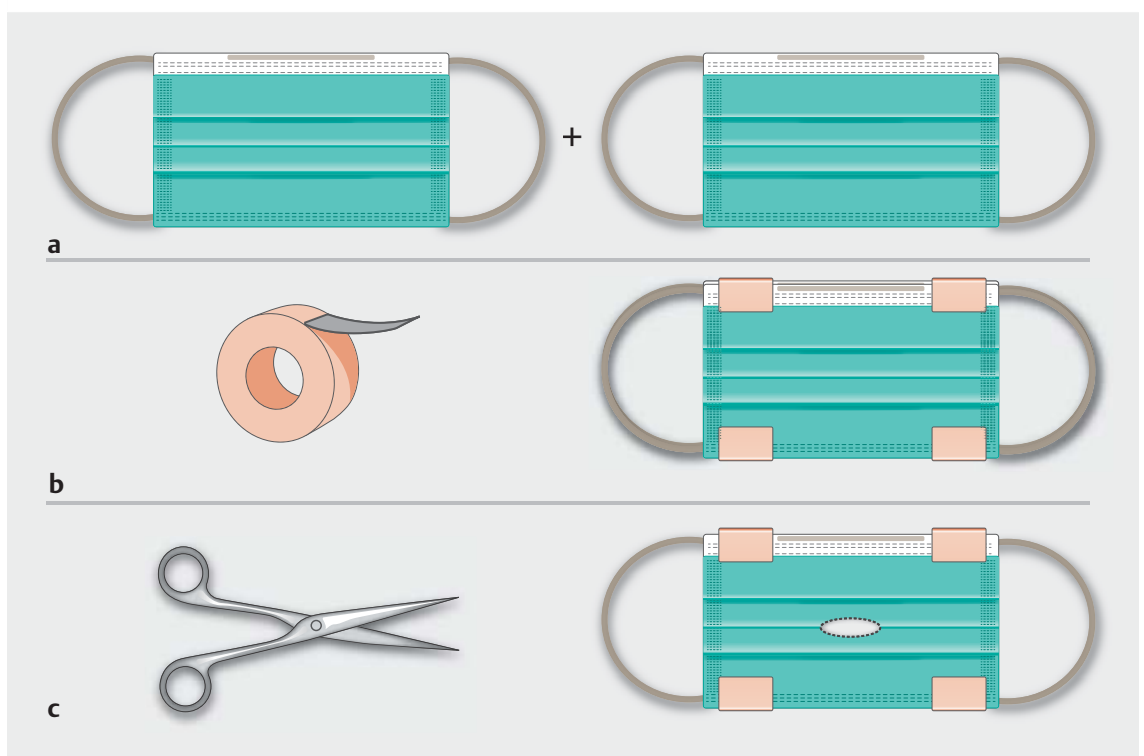

Fig. 1 Mitigation of aerosol infection risk during upper gastrointestinal endoscopy: simple construction of the "double surgical mask with slit." a Two individual universal surgical masks. $\mathbf{b}$ The masks are taped together to form a double surgical mask. c A narrow slit (length $1.2 \mathrm{~cm}$ ) is cut through the double mask, using scissors.

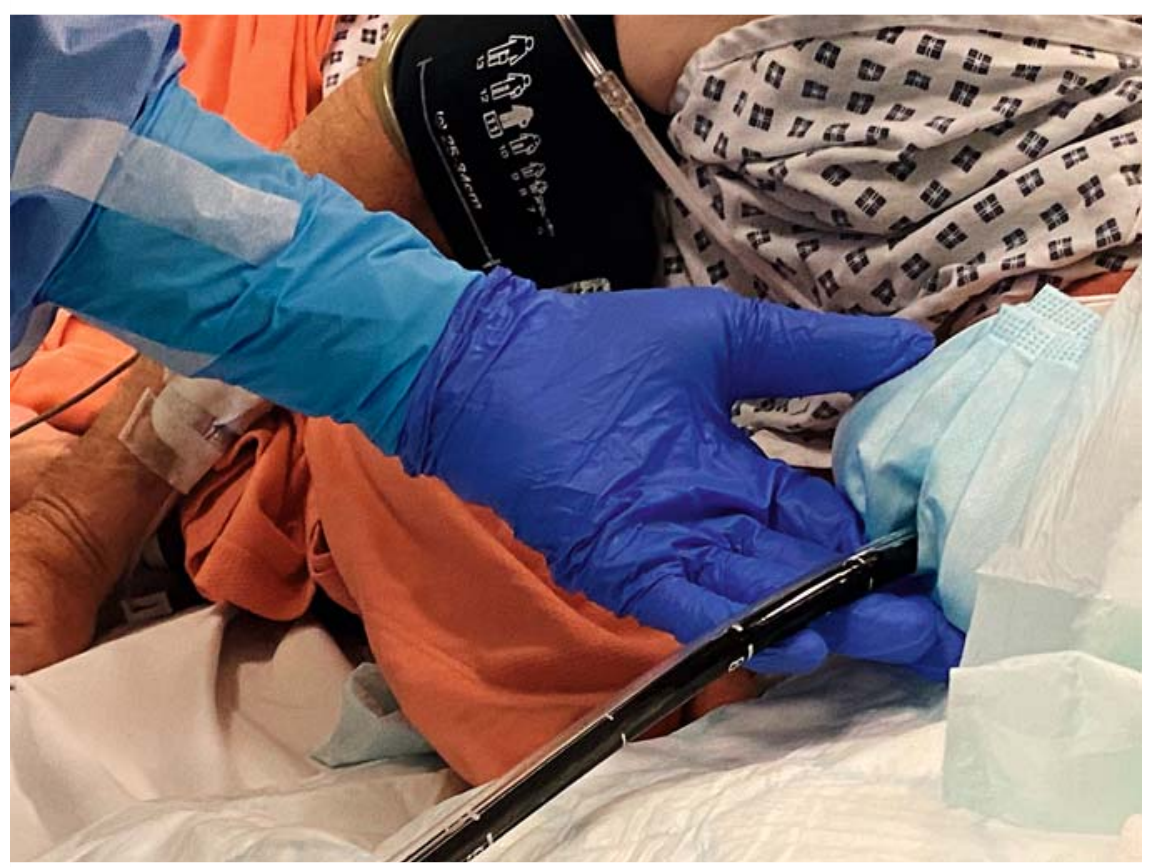

Fig. 2 The "double surgical mask with slit" being used in clinical practice during anterograde double-balloon enteroscopy. 
endoscopy: time to move forward?" hosted by the European Society for Gastrointestinal Endoscopy (ESGE) [5].

\section{Competing interests}

Alberto Murino has acted as a consultant for Boston Scientific and GI Supply. He has also received academic grants from Fujifilm, Aquilant Endoscopy, Norgine, and Olympus. Edward J. Despott has acted as a consultant for Boston Scientific and Ambu. He has also received academic grants and speaker honoraria from Fujifilm, Aquilant Endoscopy, Norgine, and Olympus. The other authors declare that they have no conflict of interest.

The authors

Nikolaos Lazaridis, Alexandros Skamnelos, Alberto Murino, Rocio Chacchi Cahuin, Nikolaos Koukias, Edward J. Despott Royal Free Unit for Endoscopy, The Royal Free Hospital and University College London (UCL) Institute for Liver and Digestive Health, London, UK
Corresponding author

\section{E.J. Despott, MD FRCP FASGE MD(Res)}

The Royal Free Hospital and UCL Institute for Liver and Digestive Health, Pond Street, London NW3 2QG, United Kingdom Fax: +44-20-74315261

edespott@doctors.org.uk

\section{References}

[1] Gralnek IM, Hassan C, Beilenhoff U et al. ESGE and ESGENA Position Statement on gastrointestinal endoscopy and the COVID19 pandemic. Endoscopy 2020; 52: 483490. doi:10.1055/a-1155-6229

[2] Marchese M, Capannolo A, Lombardi L et al. Use of a modified ventilation mask to avoid aerosolizing spread of droplets for short endoscopic procedures during coronavirus COVID-19 outbreak. Gastrointest Endosc 2020: doi:10.1016/j.gie.2020.03.3853

[3] Sagami R, Nishikiori H, Sato T et al. Endoscopic shield: barrier enclosure during the endoscopy to prevent aerosol droplets during the COVID-19 pandemic. VideoGIE 2020: doi:10.1016/j.vgie.2020.05.002
[4] Maclntyre CR, Chughtai AA. A rapid systematic review of the efficacy of face masks and respirators against coronaviruses and other respiratory transmissible viruses for the community, healthcare workers and sick patients. Int J Nurs Stud 2020; 103629: doi:10.1016/j.ijnurstu.2020.103629

[5] Gralnek IM, Hassan C, Pellisé M et al. COVID19 in endoscopy: time to move forward? 20 May 2020 19:00 (CEST) ESGE Webinar Series; https://www.esge.com/elearning/webinars/

\section{Bibliography}

Endoscopy 2020; 52: 928-929

DOI 10.1055/a-1198-5471

ISSN 0013-726X

(c) 2020. Thieme. All rights reserved.

Georg Thieme Verlag KG Rüdigerstraße 14, 70469 Stuttgart, Germany 